\title{
Watchful waiting is an Acceptable Treatment Option for Primary Ocular Adnexal Mucosa-associated Lymphoid Tissue Lymphoma: A Retrospective Study
}

\author{
Kentaro Mizuhara \\ Kyoto Prefectural University of Medicine
}

Tsutomu Kobayashi ( $\nabla$ t-koba@koto.kpu-m.ac.jp )

Kyoto Prefectural University of Medicine

\section{Mitsushige Nakao \\ Otsu City Hospital}

\section{Ryoichi Takahashi}

Omihachiman Community Medical Center

\section{Hiroto Kaneko}

Aiseikai Yamashina Hospital

\section{Kazuho Shimura}

Aiseikai Yamashina Hospital

Koichi Hirakawa

Fukuchiyama City Hsopital

Nobuhiko Uoshima

Japanese Red Cross Kyoto Daini Hospital

Katsuya Wada

Matsushita Memorial Hospital

\section{Eri Kawata}

Matsushita Memorial Hospital

\section{Reiko Isa}

Kyoto Prefectural University of Medicine

\section{Takahiro Fujino}

Kyoto Prefectural University of Medicine

\section{Taku Tsukamoto}

Kyoto Prefectural University of Medicine

\section{Shinsuke Mizutani}

Kyoto Prefectural University of Medicine

\section{Yuji Shimura}

Kyoto Prefectural University of Medicine

Akiko Yoneda 
Kyoto Prefectural University of Medicine

\section{Akihide Watanabe}

Kyoto Prefectural University of Medicine

\section{Chie Sotozono}

Kyoto Prefectural University of Medicine

Junya Kuroda

Kyoto Prefectural University of Medicine

\section{Research Article}

Keywords: primary ocular adnexal marginal zone lymphoma of mucosa associated lymphoid tissue, watchful and waiting, radiotherapy, rituximab monotherapy, asymptomatic patients

Posted Date: August 3rd, 2021

DOl: https://doi.org/10.21203/rs.3.rs-677385/v1

License: (c) (1) This work is licensed under a Creative Commons Attribution 4.0 International License. Read Full License 


\section{Abstract}

\section{Background:}

Primary ocular adnexal mucosa-associated lymphoid tissue (MALT) lymphoma (POAML) is the most common subtype of ocular adnexal lymphomas, and most patients with POAML show an indolent clinical course and achieve long-term survival. Although radiotherapy (RT) is the standard of care for localized POAML, it can occasionally lead to permanent side effects. Other treatment strategies, such as rituximab $(\mathrm{R})$ monotherapy and immunochemotherapy, have been used for POAML treatment, but their long-term benefits and relative merits remain unclear. Considering that watchful waiting (WW) is a potential option for some indolent lymphomas, WW is expected to be a therapeutic option for POAML. However, the benefits of WW for POAML patients are also unclear. The aim of this study is to determine the optimal treatment strategy for POAML.

\section{Methods:}

We retrospectively analyzed 75 patients who were diagnosed POAML between 2008 and 2019 in the institutions of the Kyoto Clinical Hematology Study Group.

\section{Results:}

The median age was 68 years, and 41 patients were women. Common involved sites were conjunctiva (42.7\%), orbit (36.0\%), and lacrimal gland (12.0\%), and most patients (92.0\%) presented with Ann Arbor stage IE disease. The treatment strategy was selected at the physicians' discretion, and more patients without subjective symptoms by tumor mass were subjected to WW (29 patients, 38.7\%), while more patients with tumor-derived subjective symptoms were treated by tumor-directed therapy (24 [32.0\%] received focal RT, and 19 [25.3\%] received R monotherapy). Complete response rates were $79.2 \%$ and $42.1 \%$ in the RT and R groups, respectively. At 60 months' follow-up, the estimated proportions of POAML patients not requiring new treatment were $69.4 \%, 85.2 \%$, and $53.8 \%$ in the WW, RT, and R groups, respectively. There were no significant differences in the time to start of new treatment between WW and RT groups (median: both not reached [NR], $p=0.187$ ) and between WW and R groups (median: NR vs. 69.0 months, $p=0.554$ ). No specific predictive factor for the future need of treatment was identified in the WW group.

\section{Conclusions:}

WW may be an acceptable treatment option for POAML, especially in asymptomatic patients.

\section{Background}

Primary ocular adnexal marginal zone lymphoma of mucosa-associated lymphoid tissue (MALT) (POAML) is the most frequent subtype of ocular adnexal lymphomas, accounting for $80 \%-90 \%$ of all ocular adnexal lymphomas in East Asia [1,2] and 60\% in Western countries [3]. POAML patients generally 
experience an indolent clinical course and achieve long-term survival, with the 10-year disease-specific survival exceeding $90 \%$ [4-8].

Radiotherapy (RT) is widely recognized as the standard of care for localized POAML because of its high efficacy for local control and tolerability [9-16]. However, complications, such as cataract, retinitis, dry eye, and optic neuropathy, of RT occasionally lead to irreversible damage [13-17]. Other treatment strategies, such as rituximab monotherapy [18-21], immunochemotherapy [22], intralesional rituximab [23], and antibiotic therapy for Chlamydia psittaci [24], have been used for POAML treatment, but their long-term benefits and the superiority of one strategy over others are unclear. Considering no significant difference in overall survival (OS) between watchful waiting (WW) and rituximab monotherapy or immunochemotherapy in asymptomatic patients with advanced-stage, low-grade lymphomas, such as follicular lymphoma [25-27], WW is expected to be a therapeutic option for POAML, too; however, the benefits of WW for POAML patients are unclear.

To answer this clinical question, we retrospectively investigated the disease characteristics and treatment outcomes of POAML patients diagnosed and treated in the institutes of the Kyoto Clinical Hematology Study Group (KOTOSG).

\section{Methods}

\section{Study design}

We retrospectively analyzed the background, disease status, treatments, and clinical outcomes of patients histologically diagnosed with POAML between February 2008 and September 2019 at institutes belonging to the KOTOSG. The primary ocular adnexal disease sites were defined as involvement of the conjunctiva, orbit, eyelid, or lacrimal gland. The disease stage according to the Ann Arbor staging system was evaluated via ophthalmological and physical examination, computed tomography (CT), magnetic resonance imaging (MRI), positron emission tomography CT (PET-CT), or bone marrow analysis. Bilateral ocular adnexal lymphoma without other lymphomatous involvement was defined as stage IE disease. Patients with a follow-up period of $<1$ year were excluded from analysis.

Clinical data of each patient were collected using the patient's case report form including background factors: age, gender, Eastern Cooperative Oncology Group performance status (PS), and relevant medical history, including symptoms, involved sites, International Prognostic Index (IPI), serological laboratory data, imaging data, clinical stage, and details of treatment (the degree of surgical resection, types of initial treatment, response to treatment, survival periods, and adverse events [AEs]).

\section{Analysis of treatment outcomes}

The time to start of new treatment (TTNT), progression-free survival (PFS), OS, overall response rate (ORR), complete response (CR) rate, and AEs of treatment were analyzed. The TTNT was defined as the 
interval from commencement of treatment to the date of starting next-line treatment, including systemic chemotherapy or RT. In the case of WW, the TTNT was defined as the time from diagnosis to the initiation of new treatment. In patients without the need for new treatment, survival data were censored at the date last assessed. The PFS was defined as the interval from commencement of treatment to disease progression or death, and the OS was defined as the interval from commencement of treatment to death. In the case of WW, the PFS and OS were calculated from the date of diagnosis. The PFS was censored at the start of new treatment in case patients proceeded to new treatment without disease progression. The Lugano 2014 criteria were used for response assessment [28]. AEs were graded using the National Cancer Institute Common Terminology Criteria for Adverse Events (CTCAE) version 5.0. The treatment response of ocular lesions and ocular AEs were assessed by at least two physicians, including a hematologist and an ophthalmologist.

\section{Statistical analysis}

The distribution of patient characteristics between groups was compared using Student's t-test and the Kruskal-Wallis test for continuous variables and Fisher's exact test for qualitative variables. The KaplanMeier method was performed for survival analysis, with a log-rank test for comparison of survival curves. The confidence interval $(\mathrm{Cl})$ was $95 \%$, and $p<0.05$ was considered statistically significant. All statistical analyses were performed using EZR version 1.37 [29].

\section{Results}

\section{Patient characteristics and clinical presentation in association with treatment procedure}

Overall, 103 patients were diagnosed with POAML, of which 11 were excluded from analysis because of lost follow-up, 11 due to missing data, and 6 due to short follow-up within 1 year. As a result, 75 patients were analyzed in this study. Patient characteristics are shown in Table 1. The median age was 68 years (range: $26-92$ years), and 41 patients (54.7\%) were females. The most common involved sites were the conjunctiva (42.7\%), followed by the orbit (36.0\%), lacrimal gland (12.0\%), and eyelid (8.0\%). Of the 75 patients, $69(92.0 \%)$ presented with stage IE disease, followed by $3(4.0 \%)$ with stage IVE, 2 (2.7\%) with stage IIE, and 1 with stage IIIE. In addition, 61 patients (81.3\%) presented with a unilateral ocular region, $14(18.7 \%)$ presented with bilateral disease regions, $5(6.7 \%)$ had complications with an immunoglobulin G4 (IgG4)-related disease, and 4 of them had lymphoma involvement in the lacrimal gland. According to the IPI, the majority of patients $(69,92.0 \%)$ were classified as low risk, 3 patients $(4.0 \%)$ as lowintermediate risk, $2(2.7 \%)$ as high-intermediate risk, and $1(1.3 \%)$ as high risk. The most frequent complaint at the initial presentation was the recognition of a tumor without symptoms in 29 patients, followed by swelling in 19 , hyperemia in 9 , discomfort in 7 , and other symptoms in 11 . At tumor biopsy for histopathologic diagnosis, the tumor was completely resected in 17 patients, while a residual tumor existed after biopsy in 58 patients (Table 1). 
WW was the most frequent first-line modality, selected for $29(38.7 \%)$ of 75 patients, including 14 patients with compete tumor resection at biopsy. In the remaining 46 patients $(61.3 \%)$, the primary treatment modalities were RT in 24 (52.0\%) (RT group), rituximab monotherapy in 19 (41.3\%) (R group), and other modalities in $3(6.5 \%)$, including systemic chemotherapy with rituximab plus cyclophosphamide, doxorubicin, vincristine, and prednisolone (CHOP)-like chemotherapy in 2 patients and discontinuation of methotrexate in 1 patient with rheumatoid arthritis.

Of the 29 patients in the WW group, $19(65.5 \%)$ had primary lesions in the conjunctiva, which was more frequent compared with the RT or rituximab (R) group. In addition, the tumor was completely resected in 14 patients (48.3\%) at diagnosis, which was also more frequent compared with the RT or R group. All patients except one had stage $\triangle E$ disease in the WW group. Although $6(20.7 \%)$ of the 29 patients complained of eye discomfort with foreign-body sensation caused by lymphoma, they showed no treatment-emergent symptom that could lead to vision impairment, such as ptosis, diplopia, or proptosis.

In the RT and R groups, 43 of the 46 patients had a residual tumor after biopsy. In the RT group, the orbit was the most frequent site of lymphoma, which caused treatment-emergent subjective symptoms that potentially impair visual function. The median doses of total and fractional radiation were $30 \mathrm{~Gy}$ (range: 24-30 Gy) and $2 \mathrm{~Gy}$ (range: 1.5-2 Gy), respectively. Rituximab was administered intravenously at a dose of $375 \mathrm{mg} / \mathrm{m}^{2}$ once weekly up to eight doses. Patients with bilateral disease or advanced disease tended to undergo rituximab monotherapy.

\section{Treatment response}

As shown in Table 2, the RT group successfully obtained local disease control. A CR or complete metabolic response (CMR) was achieved in 19 (79.2\%) of the 24 patients. The ORR in the R group was $73.7 \%$, and the CR or CMR was $42.1 \%$. However, five patients $(26.3 \%)$ in the R group failed in achieving an objective response and two of them underwent additional RT. Two patients who received systemic chemotherapy combined with rituximab achieved $\mathrm{CR}$, and one patient with methotrexate withdrawal showed a partial response; these three experienced no disease progression or recurrence during the observation period.

\section{Survival outcome}

With a median follow-up of 48.8 months, new treatment was added for 20 patients, including 16 with disease progression and 4 without disease progression, who underwent new treatment due to their preference. Overall, the median TTNT was not achieved in both WW and RT groups and was 69.0 months in the R group (Figure 1A). The TTNT tended to be longer in the RT group than in the WW and R groups; however, the differences were not statistically significant. At 60 months, the estimated proportion of patients not requiring new treatment was $69.4 \%$ (95\% Cl: $47.4-83.6)$ in the WW group, $85.2 \%(95 \% \mathrm{Cl}$ : 
60.2-95.1) in the RT group, and 53.8\% (95\% Cl: 26.0-75.2) in the R group. The median TTNT was 20.3 months (range: 5.9-139.3 months) in the 16 patients with disease progression.

The median PFS was not achieved in both WW and RT groups and was 45.0 months in the R group (WW vs. R group, $p=0.375$; WW vs. RT group, $p=0.301 ; \mathrm{RT}$ vs. R group, $p=0.079$ ) (Figure $1 \mathrm{~B}$ ). The 5 -year PFS was $69.5 \%$ (95\% Cl: $43.9 \%-85.2 \%$ ) in the WW group, $67.4 \%$ (95\% Cl: $34.7 \%-86.3 \%$ ) in the RT group, and $41.4 \%$ (95\% Cl: $17.4 \%-64.1 \%)$ in the R group. All patients enrolled in this study were alive at the time of analysis, so the OS was $100 \%$ during the observation period.

\section{Clinical course and predictive factor for disease progression in the WW group}

Of the 29 patients in the WW group, 9 (31.0\%) showed disease progression or recurrence, including 1 patient with systemic progression (Table 3). Of these nine patients, seven received treatment with a median TTNT of 15.6 months (range: 5.9-139.3 months): three received RT, three underwent surgical resection, and one received rituximab monotherapy, and the disease was well-controlled in all seven. The remaining two patients continued WW even after disease progression, because of no subjective symptom or organ impairment. Neither histological transformation nor mortality was observed. In the remaining 20 patients without disease progression, 1 received RT because of the patient's preference 19 months after diagnosis and 1 received rituximab monotherapy, expecting improvement of lacrimation 16 months after diagnosis. At the time of the last follow-up, 20 (69.0\%) of 29 patients did not require treatment.

To identify predictive factors for disease progression in the WW group, we compared the clinical characteristics of 9 patients with disease progression and 20 without disease progression or recurrence. We analyzed age, gender, involved site, laterality, degree of resection, and tumor size evaluated by the detection of post-biopsy tumor involvement via CT, MRI, or PET-CT. As shown in Table 4, all these factors were not significantly associated with disease progression or recurrence in the WW group. In addition, the degree of resection on diagnosis, the involved site, laterality, and the tumor size did not significantly affect the PFS in the WW group (Figure 2).

\section{AEs with RT and rituximab}

In the RT group, 16 of 24 patients (66.7\%) developed AEs: conjunctivitis (45.8\%), radiodermatitis (41.7\%), cataract (33.3\%), and dry eye (16.7\%). Most AEs were generally mild (grade 1 or 2 ), while grade 3 cataract occurred in five patients. The median time from RT initiation to onset of cataract was 35 months, and 5 patients underwent cataract surgery. In the R group, infusion-related reaction occurred in only 1 of 19 patients (5.3\%). No other AEs due to rituximab occurred.

\section{Discussion}


In our study, WW was the most commonly selected therapeutic strategy for POAML patients, and $~ 70 \%$ of patients initially subjected to WW did not experience disease progression or recurrence during five years of follow-up after diagnosis. Previous studies have also supported the clinical utility of WW [30,31]. Tanimoto et al. demonstrated that $\sim 70 \%$ of POAML patients with stage IE disease who were managed with WW did not require any treatment, with a median follow-up of 7.1 years and survival comparable to that of patients treated by RT immediately after diagnosis [30]. Another study reported frequent spontaneous regression of POAML, in which patients developed a conjunctiva tumor without any treatment [31]. These and our results indicate WW as an acceptable approach for POAML treatment, especially in patients without treatment-emergent subjective symptoms.

The selection of WW as an initial therapeutic approach seemed strongly associated with the absence of treatment-emergent subjective symptoms as well as the tumor site in a daily practice setting. In the WW group, no patients complained of treatment-emergent subjective symptoms, such as ptosis, diplopia, or proptosis, and approximately two-thirds of patients had lymphoma involvement in their conjunctiva. In addition, complete tumor resection at diagnostic biopsy might lead to the selection of WW for initial management. Indeed, 14 (48.3\%) of 29 patients in the WW group but only $3(7.0 \%)$ of 46 patients in the RT and R groups had complete tumor resection at biopsy. However, neither the TTNT nor the PFS was significantly affected by the post-biopsy tumor status, that is, the presence or absence of a residual tumor; a detectable or undetectable tumor by the imaging technique; and the tumor site in the WW group. These results suggest that the clinical outcome by using WW may be comparable to that by administering RT or rituximab monotherapy, even in POAML patients who undergo incomplete tumor resection.

Moreover, no specific clinical information was identified as a predictive factor for the future need for POAML treatment, as previously reported [30]. Needless to say, tumor debulking, such as by RT, is urgently required when the tumor causes impairment of surrounding tissues and/or visual disturbance. Combined together, WW may be a feasible management option, at least in patients with less symptomatic POAML of conjunctival origin.

RT generally provides excellent local disease control in POAML patients [9-16]. In fact, the ORR by RT was $100 \%$ in this study. The main concern with RT in POAML is eye-related AEs, especially cataracts. The incidence of radiation cataract requiring surgery has been reported to be $1 \%-32 \%$ [13-16], which is consistent with our result, accounting for $21 \%$ of cataract incidence. The favorable utility of lens shielding has been reported for the prevention of RT-induced cataract without increasing relapse [12, 13]. Given the excellent visual outcomes following cataract surgery [32], RT should not be avoided in POAML patients in case of the need for local control. In contrast, although rituximab monotherapy is considered an alternative treatment option for POAML [18-21], its efficacy remains unclear. In our study, the ORR and CR in the R group were $73.7 \%$ and $42.1 \%$, respectively, which were lower than those in the RT group. Furthermore, half of the patients in the $\mathrm{R}$ group experienced disease progression and needed new treatment within four years. These findings do not support the selection of rituximab monotherapy as the most appropriate treatment strategy for POAML. 
This study had a few limitations. First, due to the retrospective nature, the non-uniform treatment plan, and the bias in treatment selection for individual patients, caution is required in interpreting and comparing the treatment outcomes of WW, RT, and rituximab monotherapy. The WW group had limitedstage disease, while the proportion of patients with bilateral or advanced-stage disease was higher in the R group. Second, the sample size was small, which potentially decreases statistical power. Third, data on cytogenetic/molecular abnormalities were lacking. Nevertheless, our results support the utility of WW as an initial therapeutic approach for POAML in a real-world setting and also show the effectiveness of RT, especially if local tumor control is needed.

\section{Conclusion}

WW may be an acceptable treatment option for POAML patients, especially asymptomatic patients. RT also plays a primary role in local disease control in POAML. However, further prospective studies with larger sample sizes are required to confirm these results.

\section{Abbreviations}

POAML: Primary ocular adnexal marginal zone lymphoma of mucosa-associated lymphoid tissue; WW: Watchful waitng; RT: Radiotherapy; OS: Overall survival; TTNT: Time to start of new treatment; PFS: Progression-free survival

\section{Declarations}

\section{Ethics approval and consent to participate}

The study was conducted in compliance with the Guidelines for Good Clinical Practice and the Declaration of Helsinki, and the study protocol was approved by the Institutional Review Board of Kyoto Prefectural University of Medicine (protocol code ERB-C-424) and institutional review boards of individual institutes. Informed consent was waived because of the retrospective nature of the study and the analysis used anonymous clinical data.

\section{Consent for publication}

Not applicable.

\section{Availability of data and materials}

The datasets used and/or analysed during the current study are available from the corresponding author on reasonable request. 


\section{Competing interests}

J.K. has received research funding from Kyowa Kirin and Chugai Pharmaceutical; has received honoraria from Kyowa Kirin and Chugai Pharmaceutical. T.K. has received honoraria from Chugai Pharmaceutical. Others have no competing interests to declare.

\section{Funding}

Not applicable.

\section{Authors' contributions}

J.K., T.K. and K.M. analyzed and interpreted the data. J.K. and T.K. were involved in the study conception and design. K.M., M.N., R.T., H.K., K.S., K.H., N.U., K.W., E.K., R.I., T.F., T.T., S.M., Y.S., A.Y., A.W. and C.S. were involved in data acquisition. T.K. and K.M. performed statistical analysis. K.M. drafted the manuscript. J.K. and T.K. helped with revision of the manuscript. All authors read and approved the final manuscript.

\section{Acknowledgments:}

We thank all patients and their family for enrolling in this study. We also thank the following participating researchers in the Kyoto Clinical Hematology Study Group (KOTOSG) for their scientific support: T. Fujii, T. Takimoto-Simomura, S. Nakano-Akamatsu, A. Okano, M. Yamashita-Yoshida, T. Nakamura, H. Hayata, Y. Chinen, A. Miyashita, Y. Komori, N. Sasaki, Y. Tsutsumi, Y. Kamitsuji, E. Sakiyama, Y. Yamane, M. Kiyota, Y. Inoue, A. Muramatsu, H. Okamoto, A. Ohnishi, Y. Katsuragawa-Taminishi, Y. Kawaji-Kanayama, J. Yamaguchi, D. Nishiyama, Y. Matsumura-Kimoto, Y. Kobayashi, S. Horiike, and M. Taniwaki.

\section{References}

1. Mannami T, Yoshino T, Oshima K, Takase S, Kondo E, Ohara N, et al. Clinical, histopathological, and immunogenetic analysis of ocular adnexal lymphoproliferative disorders: characterization of malt lymphoma and reactive lymphoid hyperplasia. Mod Pathol. 2001;14:641-9.

2. Cho EY, Han JJ, Ree HJ, Ko YH, Kang YK, Ahn HS, et al. Clinicopathologic analysis of ocular adnexal lymphomas: extranodal marginal zone B-cell lymphoma constitutes the vast majority of ocular lymphomas among Koreans and affects younger patients. Am J Hematol.

3. Olsen TG, Holm F, Mikkelsen LH, Rasmussen PK, Coupland SE, Esmaeli B, et al. Orbital LymphomaAn International Multicenter Retrospective Study. Am J Ophthalmol. 2019;199:44-57.

4. Hindso TG, Esmaeli B, Holm F, Mikkelsen LH, Rasmussen PK, Coupland SE, et al. International multicentre retrospective cohort study of ocular adnexal marginal zone B-cell lymphoma. $\mathrm{Br} \mathrm{J}$ Ophthalmol. 2020;104:357-62. 
5. Nam SW, Woo KI, Kim YD. Characteristics of primary extranodal marginal zone B-cell lymphoma in Korea: conjunctiva versus other ocular adnexa. Br J Ophthalmol. 2018;102:502-8.

6. Desai A, Joag MG, Lekakis L, Chapman JR, Vega F, Tibshirani R, et al. Long-term course of patients with primary ocular adnexal MALT lymphoma: a large single-institution cohort study. Blood. 2017;129:324-32.

7. Masuda Y, Takeuchi K, Kodama T, Fujisaki T, Imaizumi Y, Otsuka E, Ozaki S, Hasebe S, Yakushijin Y. Treatment-associated outcomes of patients with primary ocular adnexal MALT lymphoma after accurate diagnosis. Int J Clin Oncol. 2019; 24: 1620-1628.

8. Seresirikachorn K, Norasetthada L, Ausayakhun S, Apivatthakakul A, Tangchittam S, Pruksakorn V, Wudhikarn K, Wiwatwongwana D. Clinical presentation and treatment outcomes of primary ocular adnexal MALT lymphoma in Thailand. Blood Res. 2018; 53: 307-313.

9. Galieni P, Polito E, Leccisotti A, Marotta G, Lasi S, Bigazzi C, et al. Localized orbital lymphoma. Haematologica. 1997; 82: 436-9.

10. Sasai K, Yamabe H, Dodo Y, Kashii S, Nagata Y, Hiraoka M. Non-Hodgkin's lymphoma of the ocular adnexa. Acta Oncol. 2001; 40: 485-90.

11. Lee J, Oh D, Choi BO, Eom KY, Lee JH, Kim JH, Lee SW, Suh YK, Suh CO. Patterns of care for orbital marginal zone B-cell lymphoma of mucosa-associated lymphoid tissue in Korea throughout 2016: Results from a multicenter cross-sectional cohort study (KROG 16-19). Asia Pac J Clin Oncol. 2019; 15: 358-363.

12. Lee J, Yoon JS, Kim JS, Koom WS, Cho J, Suh CO. Long-term outcome, relapse patterns, and toxicity after radiotherapy for orbital mucosa-associated lymphoid tissue lymphoma: implications for radiotherapy optimization. Jpn J Clin Oncol. 2019;49:664-70.

13. Lee Gl, Oh D, Kim WS, Kim SJ, Ko YH, Woo Kl, et al. Low-Dose Radiation Therapy for Primary Conjunctival Marginal Zone B-Cell Lymphoma. Cancer Res Treat. 2018;50:575-81.

14. Uno T, Isobe K, Shikama N, Nishikawa A, Oguchi M, Ueno N, et al. Radiotherapy for extranodal, marginal zone, B-cell lymphoma of mucosa-associated lymphoid tissue originating in the ocular adnexa: a multiinstitutional, retrospective review of 50 patients. Cancer. 2003;98:865-71.

15. Ejima Y, Sasaki R, Okamoto Y, Maruta T, Azumi A, Hayashi Y, et al. Ocular adnexal mucosaassociated lymphoid tissue lymphoma treated with radiotherapy. Radiother Oncol. 2006;78:6-9.

16. Kim, S., Yang, H. \& Yang, SW. Effects of radiation therapy on the meibomian glands and dry eye in patients with ocular adnexal mucosa-associated lymphoid tissue lymphoma. BMC Ophthalmo/ 2020; $20,24$.

17. Ferreri AJ, Ponzoni M, Martinelli G, Muti G, Guidoboni M, Dolcetti R, et al. Rituximab in patients with mucosal-associated lymphoid tissue-type lymphoma of the ocular adnexa. Haematologica. 2005;90:1578-9.

18. Mino T, Mihara K, Yoshida T, Takihara Y, Ichinohe T. Monthly administration of rituximab is useful for patients with ocular adnexal mucosa-associated lymphoid tissue lymphoma. Blood Cancer J. 2014; 4: e245. 
19. Fujita Y, Mimura M, Satou Y, Akioka T, Oku H, Ikeda T. Rituximab Monotherapy for Compressive Optic Neuropathy With Giant Ocular Adnexal Mucosa-Associated Lymphoid Tissue lymphoma. Ophthalmic Plast Reconstr Surg. 2020 Aug 18. doi: 10.1097/IOP.0000000000001803. Epub ahead of print.

20. Tuncer S, Tanyıldız B, Basaran M, Buyukbabani N, Dogan O. Systemic Rituximab Immunotherapy in the Management of Primary Ocular Adnexal Lymphoma: Single Institution Experience. Curr Eye Res. 2015; 40: 780-5.

21. Kim SY, Yang SW, Lee WS, Yang JW, Oh SY, Ahn HB, et al. Frontline treatment with chemoimmunotherapy for limited-stage ocular adnexal MALT lymphoma with adverse factors: a phase II study. Oncotarget. 2017;8:68583-90.

22. Ferreri AJM, Sassone M, Miserocchi E, Govi S, Cecchetti C, Corti ME, et al. Treatment of MALT lymphoma of the conjunctiva with intralesional rituximab supplemented with autologous serum. Blood Adv. 2020;4:1013-9.

23. Ferreri AJ, Ponzoni M, Guidoboni M, De Conciliis C, Resti AG, Mazzi B, et al. Regression of ocular adnexal lymphoma after Chlamydia psittaci-eradicating antibiotic therapy. J Clin Oncol. 2005;23:5067-73.

24. Nastoupil LJ, Sinha R, Byrtek M, Ziemiecki R, Zhou X, Taylor M, et al. Outcomes following watchful waiting for stage IIIV follicular lymphoma patients in the modern era. Br J Haematol. 2016;172:72434.

25. Ardeshna KM, Qian W, Smith P, Braganca N, Lowry L, Patrick P, et al. Rituximab versus a watch-andwait approach in patients with advanced-stage, asymptomatic, non-bulky follicular lymphoma: an open-label randomised phase 3 trial. The Lancet Oncology. 2014;15:424-35.

26. Ardeshna KM, Smith P, Norton A, Hancock BW, Hoskin PJ, MacLennan KA, et al. Long-term effect of a watch and wait policy versus immediate systemic treatment for asymptomatic advanced-stage nonHodgkin lymphoma: a randomised controlled trial. The Lancet. 2003;362:516-22.

27. Cheson B. D, Fisher R. I, Barrington S. F, Cavalli F, Schwartz L. H, Zucca E, et al. Recommendations for initial evaluation, staging, and response assessment of Hodgkin and non-Hodgkin lymphoma: the Lugano classification. J Clin Oncol. 2014;32:3059-68.

28. Kanda Y. Invetigation of the freely available easy-to-use software 'EZR' for medical statistics. Bone Marrow Transplantation. 2013;48:452-58.

29. Tanimoto K, Kaneko A, Suzuki S, Sekiguchi N, Maruyama D, Kim SW, et al. Long-term follow-up results of no initial therapy for ocular adnexal MALT lymphoma. Ann Oncol. 2006;17:135-40.

30. Matsuo T, Yoshino T. Long-term follow-up results of observation or radiation for conjunctival malignant lymphoma. Ophthalmology. 2004;111:1233-7.

31. Clark A, Morlet N, Ng JQ, Preen DB, Semmens JB. Whole population trends in complications of cataract surgery over 22 years in Western Australia. Ophthalmology. 2011;118:1055-61.

\section{Tables}


Table 1

Patient characteristics

Page 13/20 


\begin{tabular}{|c|c|c|c|c|c|c|}
\hline & $\begin{array}{l}\text { Total } \\
(n=75)\end{array}$ & $\begin{array}{l}\text { WW } \\
(n=29)\end{array}$ & $\begin{array}{l}\text { Radiotherapy } \\
(n=24)\end{array}$ & $\begin{array}{l}\text { Rituximab } \\
\text { monotherapy } \\
(n=19)\end{array}$ & $\begin{array}{l}\text { Others } \\
(n=3)\end{array}$ & $P$ \\
\hline $\begin{array}{l}\text { Median age } \\
\text { (range) }\end{array}$ & $\begin{array}{l}68(26- \\
92)\end{array}$ & $\begin{array}{l}63(37- \\
92)\end{array}$ & $68(26-85)$ & $68(58-81)$ & $\begin{array}{l}67(59- \\
78)\end{array}$ & $0.044 \dagger$ \\
\hline Gender, n (\%) & & & & & & $0.373^{*}$ \\
\hline Male / Female & $\begin{array}{l}34(45) / \\
41(55)\end{array}$ & $\begin{array}{l}10(34) / \\
19(66)\end{array}$ & $\begin{array}{l}14(58) / 10 \\
(42)\end{array}$ & $\begin{array}{l}9(47) / 10 \\
(53)\end{array}$ & $\begin{array}{l}1(33) / \\
2(67)\end{array}$ & \\
\hline $\begin{array}{l}\text { Involved site, n } \\
\text { (\%) }\end{array}$ & & & & & & $<0.001^{*}$ \\
\hline Conjunctiva & $32(43)$ & $19(66)$ & $5(21)$ & $8(42)$ & 0 & \\
\hline Orbit & $27(36)$ & $3(10)$ & $13(54)$ & $9(47)$ & $2(67)$ & \\
\hline $\begin{array}{l}\text { Lacrimal } \\
\text { gland }\end{array}$ & $9(12)$ & $5(17)$ & $2(8)$ & $2(11)$ & 0 & \\
\hline Eyelid & $6(8)$ & $1(3)$ & $4(17)$ & 0 & $1(33)$ & \\
\hline $\begin{array}{l}\text { Lacrimal } \\
\text { caruncle }\end{array}$ & $1(1)$ & $1(3)$ & 0 & 0 & 0 & \\
\hline Laterality, n (\%) & & & & & & $0.076^{*}$ \\
\hline $\begin{array}{l}\text { Unilateral / } \\
\text { Bilateral }\end{array}$ & $\begin{array}{l}61(81) / \\
14(19)\end{array}$ & $\begin{array}{l}24(83) / \\
5(17)\end{array}$ & $\begin{array}{l}22(92) / 2 \\
(8)\end{array}$ & $\begin{array}{l}14(74) / 5 \\
(26)\end{array}$ & $\begin{array}{l}1(33) / \\
2(67)\end{array}$ & \\
\hline $\begin{array}{l}\text { Degree of } \\
\text { resection, } n \text { (\%) }\end{array}$ & & & & & & $<0.001^{*}$ \\
\hline $\begin{array}{l}\text { Complete } \\
\text { resection }\end{array}$ & $17(23)$ & $14(48)$ & $1(4)$ & $2(11)$ & 0 & \\
\hline $\begin{array}{r}\text { Partial } \\
\text { resection }\end{array}$ & $58(77)$ & $15(52)$ & $23(96)$ & $17(89)$ & $3(100)$ & \\
\hline \multicolumn{7}{|l|}{$\begin{array}{l}\text { Medical history, } \\
\text { n (\%) }\end{array}$} \\
\hline $\begin{array}{l}\text { lgG4-related } \\
\text { disease }\end{array}$ & $5(7)$ & $3(10)$ & $1(4)$ & $1(5)$ & 0 & \\
\hline $\begin{array}{l}\text { Rheumatoid } \\
\text { Arthritis }\end{array}$ & $1(1)$ & 0 & 0 & 0 & $1(33)$ & \\
\hline $\begin{array}{l}\text { Sjogren's } \\
\text { syndrome }\end{array}$ & $2(3)$ & 0 & 0 & 0 & $2(67)$ & \\
\hline $\begin{array}{l}\text { Ann Arbor } \\
\text { Staging, n (\%) }\end{array}$ & & & & & & $0.047^{\star}$ \\
\hline$\nabla \mathrm{E}$ & $69(92)$ & $28(97)$ & $23(96)$ & $16(84)$ & $2(67)$ & \\
\hline
\end{tabular}




\begin{tabular}{|c|c|c|c|c|c|c|}
\hline$\nabla \mathrm{E}$ & $2(3)$ & $1(3)$ & 0 & $1(5)$ & 0 & \\
\hline$\nabla \mathrm{E}$ & $1(1)$ & 0 & 0 & 0 & $1(33)$ & \\
\hline$\nabla \mathrm{E}$ & $3(4)$ & 0 & $1(4)$ & $2(11)$ & 0 & \\
\hline IPI, n (\%) & & & & & & $0.054^{\star}$ \\
\hline Low & $69(92)$ & $29(100)$ & $22(92)$ & $16(84)$ & $2(67)$ & \\
\hline $\begin{array}{l}\text { Low- } \\
\text { intermediate }\end{array}$ & $2(3)$ & 0 & $1(4)$ & $1(5)$ & 0 & \\
\hline $\begin{array}{l}\text { High- } \\
\text { intermediate }\end{array}$ & $3(4)$ & 0 & $1(4)$ & $2(11)$ & 0 & \\
\hline High & $1(1)$ & 0 & 0 & 0 & $1(33)$ & \\
\hline \multicolumn{7}{|l|}{$\begin{array}{l}\text { Presentation, } n \\
\text { (\%) }\end{array}$} \\
\hline $\begin{array}{l}\text { Tumor } \\
\text { recognition }\end{array}$ & 29 (39) & $13(45)$ & $9(38)$ & $6(32)$ & $1(33)$ & \\
\hline Swelling & $19(25)$ & $7(24)$ & $8(33)$ & $3(16)$ & $1(33)$ & \\
\hline Discomfort & $7(9)$ & $6(21)$ & 0 & $1(5)$ & 0 & \\
\hline Hyperemia & $9(12)$ & $3(10)$ & 0 & $6(32)$ & 0 & \\
\hline Ptosis & $6(8)$ & 0 & $4(17)$ & $1(5)$ & $1(33)$ & \\
\hline Diplopia & $3(4)$ & 0 & $1(4)$ & $2(11)$ & 0 & \\
\hline Proptosis & $1(1)$ & 0 & $1(4)$ & 0 & 0 & \\
\hline Incidental & $1(1)$ & 0 & $1(4)$ & 0 & 0 & \\
\hline
\end{tabular}

IPI, International Prognostic Index; POAML, primary ocular adnexal marginal zone lymphoma of mucosa-associated tissue.

* Fisher's exact test.

† Kruskal-Wallis test.

Table 2

Response to initial POAML treatment 


\begin{tabular}{ll} 
Radiotherapy, $\boldsymbol{n}$ (\%) & $(\mathrm{n}=24)$ \\
\hline CR/CMR & $19(79.2)$ \\
\hline PR & $5(20.8)$ \\
\hline SD & 0 \\
\hline PD & 0 \\
\hline ORR & $24(100)$ \\
\hline Rituximab monotherapy, $\boldsymbol{n}$ (\%) & $(\mathrm{n}=19)$ \\
\hline CR/CMR & $8(42.1)$ \\
\hline PR & $6(31.6)$ \\
\hline SD & $5(26.3)$ \\
\hline PD & 0 \\
\hline ORR & $14(73.7)$ \\
\hline Chemotherapy combined with rituximab, $n(\%)$ & $(\mathrm{n}=2)$ \\
\hline CR/CMR & $2(100)$ \\
\hline PR & 0 \\
\hline SD & 0 \\
\hline PD & 0 \\
\hline ORR & $2(100)$ \\
\hline Discontinuation of MTX, $\boldsymbol{n}$ (\%) & $(\mathrm{n}=1)$ \\
\hline CR/CMR & 0 \\
\hline PR & $1(100)$ \\
\hline SD & 0 \\
\hline PD & 0 \\
\hline ORR & $1(100)$ \\
\hline$P O A M$ & 0 \\
\hline
\end{tabular}

POAML, primary ocular adnexal marginal zone lymphoma of mucosa-associated tissue; $C R$, complete response; CMR, complete metabolic response; PR, partial response; SD, stable disease; PD, progressive disease; ORR, over all response; MTX, methotrexate;

\section{Table 3}

Characteristics of 9 POAML patients who experienced disease progression during WW 


\begin{tabular}{|c|c|c|c|c|c|c|c|}
\hline Age & Gender & Stage & Laterality & $\begin{array}{l}\text { Involved } \\
\text { site }\end{array}$ & $\begin{array}{l}\text { Degree of } \\
\text { resection } \\
\text { at biopsy }\end{array}$ & $\begin{array}{l}\text { Site of } \\
\text { progression }\end{array}$ & Next treatment \\
\hline 40 & $\mathrm{~F}$ & $\triangle \mathrm{E}$ & right & conjunctiva & complete & OA & $\begin{array}{l}\text { Surgical } \\
\text { resection }\end{array}$ \\
\hline 42 & $\mathrm{~F}$ & $\nabla \mathrm{E}$ & right & conjunctiva & complete & $\mathrm{OA}$ & $\begin{array}{l}\text { Surgical } \\
\text { resection }\end{array}$ \\
\hline 38 & $\mathrm{~F}$ & $\nabla \mathrm{E}$ & left & conjunctiva & complete & OA & Radiotherapy \\
\hline 74 & $\mathrm{~F}$ & $\nabla \mathrm{E}$ & left & conjunctiva & complete & $\mathrm{OA}$ & $\begin{array}{l}\text { Watchful } \\
\text { waiting }\end{array}$ \\
\hline 54 & $M$ & $\nabla \mathrm{E}$ & left & conjunctiva & partial & OA & $\begin{array}{l}\text { Surgical } \\
\text { resection }\end{array}$ \\
\hline 73 & $M$ & $\nabla \mathrm{E}$ & left & conjunctiva & partial & OA & Radiotherapy \\
\hline 61 & $M$ & $\nabla \mathrm{E}$ & bilateral & conjunctiva & partial & OA & $\begin{array}{l}\text { Watchful } \\
\text { waiting }\end{array}$ \\
\hline 74 & M & $\nabla \mathrm{E}$ & bilateral & $\begin{array}{l}\text { lacrimal } \\
\text { gland }\end{array}$ & partial & $O A$ & Radiotherapy \\
\hline 54 & $M$ & $\nabla \mathrm{E}$ & right & $\begin{array}{l}\text { lacrimal } \\
\text { gland }\end{array}$ & partial & systemic & $\begin{array}{l}\text { Rituximab } \\
\text { monotherapy }\end{array}$ \\
\hline
\end{tabular}

$\mathrm{F}$, female; $\mathrm{M}$, male; $\mathrm{OA}$, ocular adnexal region; $\mathrm{POAML}$, primary ocular adnexal marginal zone lymphoma of mucosa-associated tissue; WW, watchful waiting.

\section{Table 4}

Comparison of characteristics of POAML patients managed with WW with and without disease progression 


$\begin{array}{ll}\text { No progression } & \text { Progression } \\ (n=20) & (n=9)\end{array}$

Age

$0.185 \dagger$

Median (range)

$63(37-92)$

$62(38-74)$

Gender, n (\%)

$0.205^{\star}$

Male / Female

$5(25) / 15(75)$

$5(56) / 4(44)$

Involved site, $\mathbf{n}(\%)$

0.431 *

Conjunctiva

$12(60)$

7 (78)

Others

$8(40)$

$2(22)$

Laterality, n (\%)

$0.633^{*}$

Unilateral

17 (85)

7 (78)

Bilateral

$3(15)$

2 (22)

Degree of resection, $n$ (\%)

$1.000 *$

Complete resection

$10(50)$

4 (44)

Partial resection or biopsy

$10(50)$

$5(56)$

\section{Tumor size, n (\%)}

$\begin{array}{llll}\text { Detectable } & 7(35) & 2(22) & 0.675^{*} \\ \text { Undetectable } & 13(65) & 7(78)\end{array}$

IPI, International Prognostic Index; POAML, primary ocular adnexal marginal zone lymphoma of mucosa-associated tissue; WW, watchful waiting.

* Fisher's exact test.

† Student's $t$-test.

\section{Figures}


Figure 1

(A)

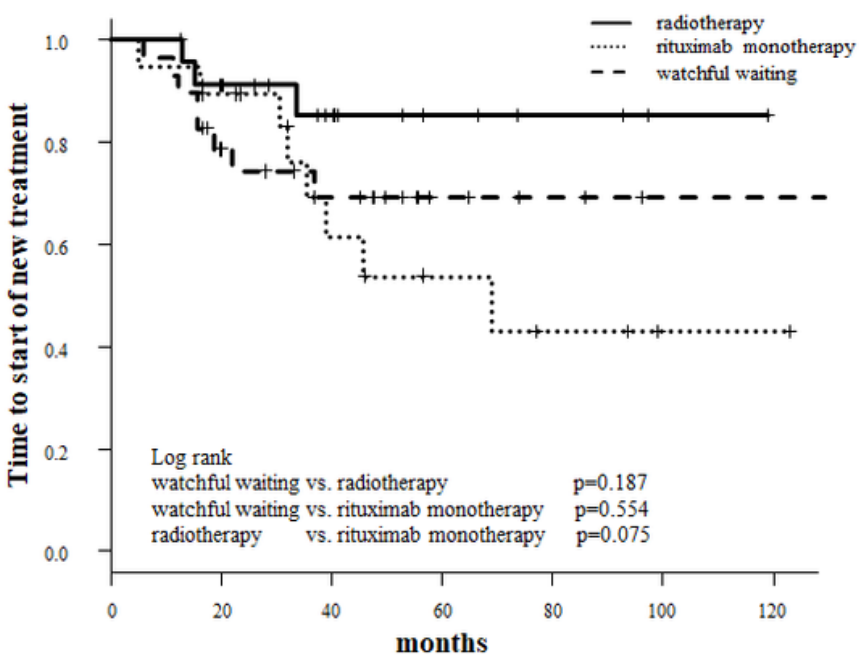

Number at risk

radiaotherapy

radiaotherapy
rituximab monotherapy
watchful waiting

\section{Figure 1}

Kaplan-Meier curves for (A) time to start of new treatment (TTNT) and (B) progression-free survival (PFS) according to treatment modalities. There was no statistically significant difference in both the

TTNT and the PFS between treatment modalities.
(B)

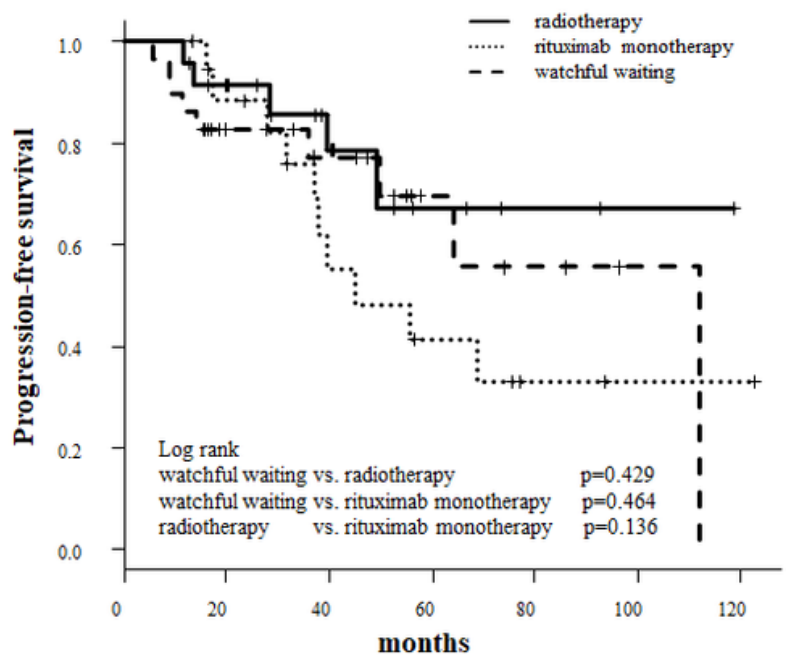

Number at risk radiotherapy $\begin{array}{lllrllll}\text { rituximab monotherapy } & 19 & 15 & 8 & 5 & 2 & 1 & 1 \\ \text { watchful waiting } & 29 & 18 & 13 & 5 & 3 & 1 & 0\end{array}$ 
Figure 2

(A)

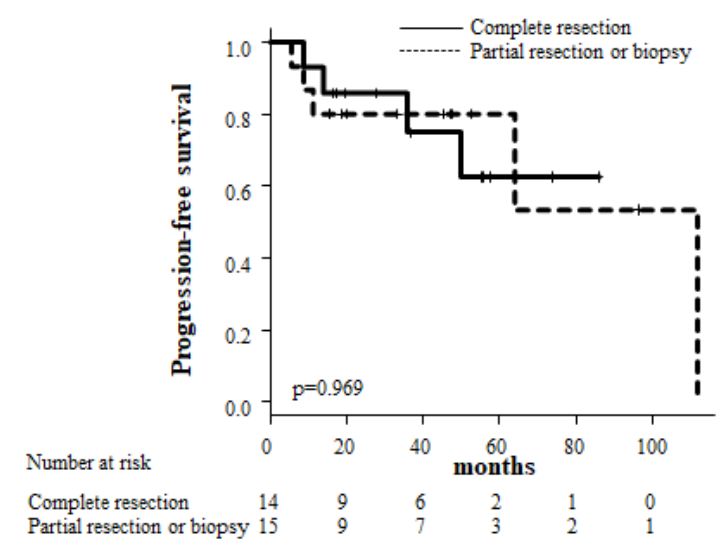

(C)

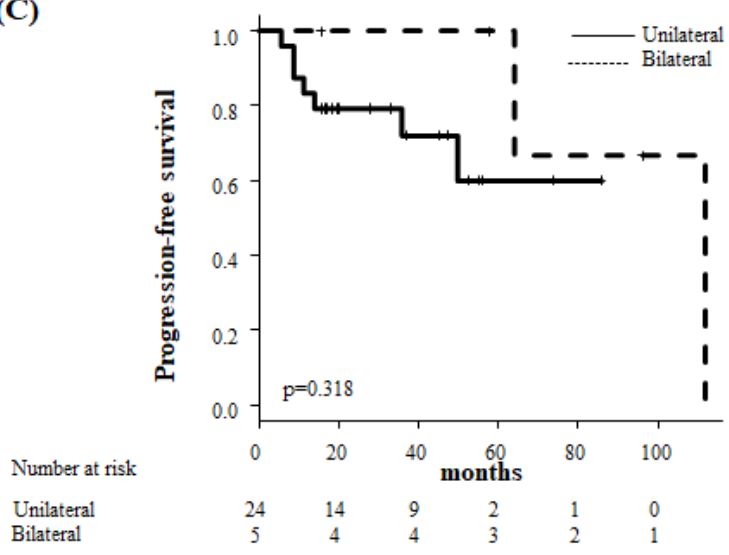

(B)

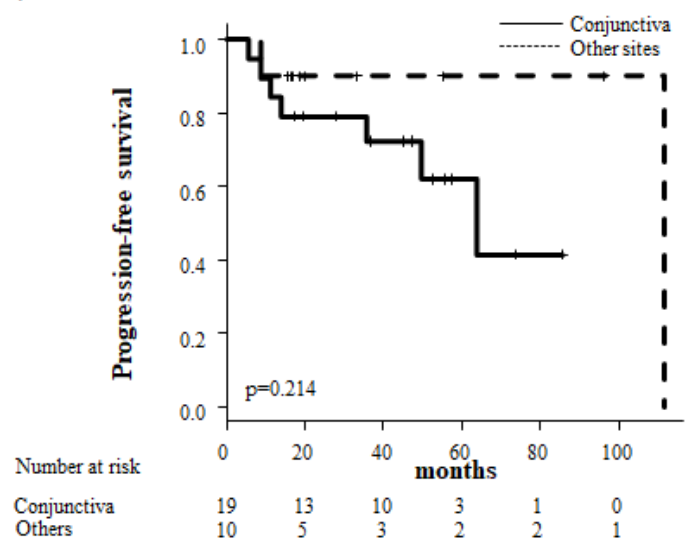

(D)

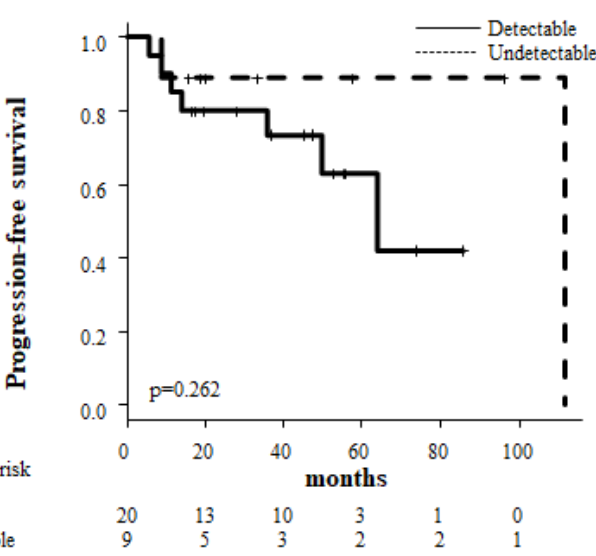

Figure 2

Kaplan-Meier curves of progression-free survival (PFS) in primary ocular adnexal marginal zone lymphoma of mucosa-associated tissue (POAML) managed with watchful waiting (WW) according to the degree of resection at biopsy (A), the involved site (B), laterality (C), and the tumor size (D). 